Portland State University

PDXScholar

Communication Faculty Publications and

Presentations

Communication

$4-1-2008$

\title{
Hair of the Frog and other Empty Metaphors: The Play Element in Figurative Language
}

\author{
L. David Ritchie \\ Portland State University, cgrd@pdx.edu \\ Valrie Dyhouse \\ Portland State University
}

Follow this and additional works at: https://pdxscholar.library.pdx.edu/comm_fac

Part of the Communication Commons

Let us know how access to this document benefits you.

\section{Citation Details}

Published as: Ritchie, L. D., \& Dyhouse, V. (2008). Hair of the frog and other empty metaphors: The play element in figurative language. Metaphor and Symbol, 23(2), 85-107.

This Post-Print is brought to you for free and open access. It has been accepted for inclusion in Communication Faculty Publications and Presentations by an authorized administrator of PDXScholar. Please contact us if we can make this document more accessible: pdxscholar@pdx.edu. 


\title{
Hair of the Frog and other Empty Metaphors:
}

\section{The Play Element in Figurative Language}

\author{
L. David Ritchie \\ cgrd@pdx.edu \\ Valrie Dyhouse \\ valriedyhouse@verizon.net \\ Department of Communication \\ Portland State University \\ Portland, OR 97207 \\ (503) 725-3550
}

Metaphor and Symbol, 23, 85-107.

Authors' Note:

This essay took shape during discussions in the graduate research seminar, Sp

556. We are indebted to Wynde Dyer, Gloria Hinkle, Chris Richter, Nate Roberts, and Sylvia Sissel for their many novel insights, useful suggestions, and provocative questions.

We are also indebted to Ray Gibbs and one anonymous reviewer for many helpful criticisms and suggestions. 


\begin{abstract}
In this essay we discuss a class of apparently metaphorical idioms, exemplified by “fine as frog's hair," that do not afford any obvious interpretation, and appear to have originated, at least in part, in language play. We review recent trends in both play theory and metaphor theory, and show that a playful approach to language is often an important element in the use and understanding of metaphors (and idioms generally), even when metaphors can be readily interpreted by means of a vehicle-to-topic mapping. Based on this evidence we call for a more deliberate inclusion of language play in metaphor theory and analysis.
\end{abstract}




\section{Hair of the Frog and other Empty Metaphors:}

\section{The Play Element in Figurative Language}

Many conventional theories of metaphor treat figurative language as primarily linguistic, usually relying on an implicit “container” or “code” theory of language (Reddy, 1993), in which metaphors have a discoverable correspondence to meanings, and could in principle be translated into literal statements of the same underlying idea. Some theorists argue that a metaphor creates an abstract category based on the vehicle; for example, "my lawyer is a shark" locates the topic, "my lawyer" in an abstract category typified by “sharks” (Glucksberg \& Keysar, 1993) A related explanation, advanced by Chiappe and Kennedy (2001) among others, treats figurative language as a matter of “transferring” abstract qualities, in this example, qualities of relentlessness and viciousness associated with sharks, from vehicle to topic (for a discussion and critique, see also Ritchie, 2003a; 2006).

In a radical departure from conventional approaches, Conceptual Metaphor Theory (Lakoff \& Johnson, 1980; 1999) turns the conventional linguistic argument on its head, with the proposal that metaphors are fundamentally conceptual, and that the verbal metaphors observed in everyday discourse are expressions of underlying conceptual relationships. The most convincing examples are the everyday expressions, regarded by conventional linguistic approaches as "dead” metaphors and thus not really figurative at all, such as "warm” or "close” relationship, “face the facts," "I see what you mean.” Although there is considerable empirical evidence in support of the fundamental claims of Conceptual Metaphor Theory (for detailed reviews see Gibbs, 1994; 2006), subsequent 
attempts to extend and elaborate the theory to encompass more complex and sophisticated metaphors have been challenged on both conceptual and empirical grounds (see, for example, Glucksberg, 1993; Ritchie, 2003b; 2006; Vervaeke and Kennedy, 1996).

Keysar and Bly (1999) report that subjects often give idiosyncratic explanations for metaphors, even when the metaphor vehicle is so obscure that the metaphor is apparently uninterpretable, for example “the goose hangs high.” Metaphors of another type, in which the vehicle at least seems to make sense, were also given a wide variety of interpretations, many of them mutually contradictory. For example, “warm his britches” was interpreted as a reference to punishment by some subjects, but others interpreted it in terms of praise. Gibbs (1998; personal communication) points out that most of the idioms studied by Keysar and Bly are metonymic rather than metaphorical in origin: to continue with the same example, “warm his britches” originally referred to the oncecommon practice of punishing disobedient children with a willow switch or a leather belt or strap, which brings blood to the surface of the skin and creates a literal, physical sensation of warmth.

However, other, more clearly metaphorical, expressions are also frequently interpreted in quite diverse ways, for example "toe the line," often understood as "tow the line” (Ritchie, 2006). These alternative spellings imply very distinct underlying conceptual metaphors, which might be expressed as something like "THE OFFICIAL DOCTRINE IS A LINE ON A MILITARY PARADE GROUND” and “THE OFFICIAL DOCTRINE IS A BARGE AND THE INDIVIDUAL IS A TUG-BOAT.” Although the two versions have somewhat different implications ("toe” suggests passive compliance, "tow" 
suggests more active compliance), the implied acquiescence to authority is sufficiently similar in quality that participants in a conversation might never realize they interpret the metaphor in entirely different ways.

These and other similar examples do not necessarily negate the usefulness of either Conceptual Metaphor Theory or primarily linguistic theories such as Categorization or Attribute-Transfer Theory, but they do suggest the need for a more complex account (Ritchie, 2006). In particular, these and other similar examples are consistent with Vervaeke and Kennedy's claim that there is not necessarily any one fixed mapping between a metaphorical expression and a particular underlying conceptual or “root” metaphor (1996; see also Ritchie, 2003b). Particularly interesting is the possibility that communicative purposes can be accomplished even when the participants do not share a common underlying "meaning” of a phrase, as illustrated by "toe / tow the line." Finally, these expressions, along with other common idioms that may have once been based on metaphors that are no longer recoverable (“kick the bucket”) suggest that the use of metaphorical expressions may be "meaningful” in itself, independently of how or even whether the metaphor is actually interpreted (Ritchie, 2006).

In this essay, we discuss a class of figurative expressions that seem to be used primarily for their playful quality, rather than for any translatable meaning, category assignment, or conceptual mapping. We suggest that many apparently metaphorical expressions are not necessarily intended to be interpreted, at least not in the usual sense implied by conventional discussions. We further argue that many apparently metaphorical expressions are based not on the more usual vehicle-topic relationships stipulated by linguistic theorists such as Glucksberg and Keysar (1993) and Chiappe and 
Kennedy (2001), nor on the embodied conceptual metaphors stipulated by theorists such as Lakoff and Johnson (1980), but rather on an intentionally playful and creative use of language (Carter, 2004; Cook, 2000). We refer to these as “empty metaphors,” following the CONTAINER / CONDUIT metaphor described by Reddy (1993), inasmuch as they either lack task-related “content” altogether, or are used with little regard for possible “content."

In this essay we will discuss several examples of intentionally playful expressions, and propose a theoretical account of how social meaning can be created on the basis of pure language play, independent of semantic or conceptual “content” of language. We begin with a review and extension of current theories of play, particularly with respect to the still under-theorized phenomenon of adult play, then return to an analysis of several examples of empty metaphors. Finally, we argue that a playful element may inform many instances of metaphoric language, even when an underlying semantic or conceptual basis is clearly intended for interpreting the metaphor.

\section{A more playful approach to play}

It is something of a truism that humor theory tends to be singularly humorless, and play theories anything but playful. There is an occasional admission that some adults do, sometimes, play, but this is usually mitigated by shifting the focus at once to "child's play” (e.g., Bateson, 2005), or by focusing primarily on humor and apparently playful language as thinly-disguised aggression (Zillmann \& Cantor, 1976) or mock combat in the service of social status. Theorists often ignore light-hearted or whimsical play altogether, and treat adult "play" as synonymous with competitive games of skill and/or chance (e.g., Malaby, 2006; 2007). It seems as if there would be something shameful 
about admitting that adults might actually engage in - and derive pleasure from - any genuinely frivolous behavior (Sutton-Smith, 1995; Sherzer, 2002).

It is possible, of course, to define play in such a way that only juveniles do it, or even in such a way that only human children do it. But any such definition would have an arbitrary quality to it, and would leave out a large class of behaviors that seem to fit the concept. For our purposes the most useful definition might start with what play is not - play is not the single-minded pursuit of survival needs. Play is done primarily for its own sake, or for the sake of the pleasure it gives, independently of any incidentally beneficial outcomes. The gambler who wins a bet and thus accomplishes economic ends may still be engaged in play. For some professional athletes, it appears that the game has ceased to be play, but for others, it is still play, even though they are paid handsomely for doing it - and by the same token, it appears that for some stockbrokers "playing" the market is literally descriptive of the pleasure they take from exercising their patternrecognition and puzzle-solving skills.

Various forms of play are observed among juveniles of many species, primarily mammals but including some birds and fish (Bateson, 2005). Commonly observed playful behaviors include stylized jumping and running, mock hunting (stalking and pouncing on inanimate objects), mock nurturing (carrying an inanimate object or an inappropriate animal around and treating it in effect as a "baby doll”), the mock combat of "rough and tumble” play. One common theory is that these behaviors serve purposes such as rehearsal for vital adult activities that they resemble. Thus, when juveniles of “prey” species such as horses and deer jump and run about, they are rehearsing behaviors that may help them elude predators, as well as familiarizing themselves with the features 
of their environment that may be useful in taking evasive action. When juveniles of predator species stalk and pounce, they may be rehearsing hunting behaviors. Rough and tumble play may serve as rehearsal for sexual and social hierarchical competitions to come, and may at the same time serve to establish the juvenile's place in an emergent social hierarchy vis-à-vis other juveniles of the troop or herd.

Among human juveniles, competitive games, particularly competitive team games, help the child develop and practice a behavioral repertoire that will be of obvious use in the modern capitalist economy (Cook, 2000). By turns, the child may practice being both a "team player” and, perhaps, a "leader.” Among humans, the repertoire of play is greatly expanded to include language and communication play, beginning with social interactive games such as "peek-a-boo” and the endless babbling of pre-linguistic infants. These simple games are important for laying the foundation for acquiring language and other communicative skills, and the honing of cognitive skills such as object constancy and perspective-taking (Cook, 2000).

Even when there are obvious benefits to reproductive fitness such as building strength and coordination, rehearsing skills, and sorting out social relationships, the potential net contribution to its (eventual) reproductive success cannot provide the motivation for these activities, since the juvenile animal knows nothing of "reproductive fitness.” It is possible that the simpler forms of play might happen through a kind of reflex, similar to the sucking reflex of a newborn infant, and indeed some of the language-play of human infants, such as the babbling of endless strings of meaningless syllables that precede an infant's first recognizable words (Lee, 1986), certainly seems to have a reflexive quality. However, a muscular reflex doesn't seem adequate to explain 
the more complex forms of animal play, much less the human child's love of skip-rope rhymes, silly puns, and other nonsensical word-play (Carter, 2004; Cook, 2000).

What can provide a motivation is that these activities are pleasurable - in physiological terms, they stimulate the release of endorphins, the activation of "pleasure circuits,” associated with a kind of self-administered temporary "high.” Both introspection and observation suggests that "play" of various forms is indeed pleasurable, sometimes intensely so. The chance to play is itself a motivation that can be as effective as food in conditioning experiments (Fagen, 1995). Because these behaviors are pleasurable, the animal will engage in them whenever the demands of more urgent needs (fear, hunger) allow it.

There is no reason to believe that the ability to self-administer endorphins by engaging in playful behavior disappears as the juvenile matures into adulthood, even if the benefits to reproductive fitness are largely achieved during childhood. Adults of many species, including humans, continue to engage in various forms of play, and not all of it is of a sort that has any obvious benefits for reproductive fitness. It is difficult to explain human adults’ engagement in punning, writing haiku or sonnets, puzzles, snorkeling, scuba diving, skiing, hiking, rock-climbing, needle-point, and so on except in terms of intrinsically-motivated play. But adults also have their own versions of playing house, cops and robbers, and other childish role-playing: Adults dress up in antique uniforms and re-enact historical battles; they dress up in medieval costumes and enact scenes from the age of chivalry; they dress up as characters from Star Trek (Wise, 1979) and The Rocky Horror Picture Show (Sharman, 1975) for no apparent reason other than 
the sheer playful enjoyment of it. Adults play. Their play is often more sophisticated than that of children, but play it is, and it seems to bring us great pleasure.

There has been a tendency in the literature to suggest that adult versions of play are always or predominantly competitive, based on skill, chance, or both (e.g., Huizinga, 1955; Malaby, 2006; 2007). But the relationship between playfulness and competition is more complex than the standard account, and the human proclivity for competition and for games of chance is balanced by a frequently-expressed preference for noncompetitive forms of play, and for limiting the competitive elements of even nominally competitive sports in many social circumstances (Kohn, 1986). Norrick (1993) shows how even overtly aggressive forms of language play such as mocking and teasing, within an intimate social group such as a family or circle of friends, can often enhance rather than undermine affection and group solidarity. Among other things, by showing that the relationship need not be constrained with the formalities of ordinary politeness they demonstrate a higher level of mutual trust and solidarity. Joking and language play generally help to demonstrate common ground, and provide a means to amuse - that is to say, to provide pleasure for - others in the group (Norrick, 1993).

Dunbar’s (1996) theory of language as an extension of primate grooming is generally consistent with Norrick’s findings. Among other primates, in particular chimpanzees, grooming provides a means of building and maintaining relationships and thus securing the animal's position in the hierarchy of the troop. It is also used to reestablish amicable relationships after a quarrel, thus helping to maintain the solidarity of the group and avoid potentially hazardous social disruptions. Pointing out that language allows an individual to "groom” up to three or four others at once, and also provides a 
way to maintain and share knowledge of an extensive set of social relationships (who's grooming whom), Dunbar argues that the use of language for such social purposes - in effect, as he puts it, for gossip - supports a primary group size as much as four times as large as that of chimpanzees. An implication is that the "grooming" - mutual pleasureinducing - functions of language are likely to be intermixed with the "task-oriented" functions. Meaningless or "empty" language may fulfill the "grooming” functions as well as or even better than meaningful language, since the key to its effect is the pleasure it gives rather than the meaning it allows the hearer to construct.

Language play can serve group cohesion and structure in several ways. To the extent that we find pleasure in word play, clever puns, and various forms of verbal humor, by telling jokes or making puns we give pleasure to one another, and thus cement amicable relationships. But as Norrick (1993) also points out, various forms of joking also provide a "safe" and acceptable way to make mild criticisms and thus reinforce group behavioral norms. Word-play and joking in various forms also provides a way to demonstrate linguistic and social skills (and knowledge), and thus to build and maintain social status. Conversely, joking and word play also, to the extent that they build on specialized knowledge, provide a test of listeners’ skills and knowledge (Cook, 2000; Norrick, 1993), and thus of the listeners’ membership and status with respect to the group. But as Norrick points out, this kind of "test of skill” is itself a source of pleasure to the listeners, and is not necessarily aggressive in either intent or effect.

Language play. Language play, by adults as well as infants, includes both exploitation and distortion of every feature of language, including phonology, lexis, and grammar (Cook, 2000; Johnson-Laird, 1993). For example, poetry, and the poetic effects 
achieved by fine prose and spoken rhetoric, make use of phonology in its use of rhyme, alliteration, and rhythm, of lexis and grammar in double entendres as well as in metaphors, metonyms, and irony. ${ }^{1}$ Each of these elements can also be deployed in less formal play, in the nonsense rhymes, nursery rhymes, and other word play heard on playgrounds everywhere, and in the playful talk of adults.

Citing Roger Caillois, Cook (2000) lists four categories of play, agon, or competion, alea, games of chance, mimicry, and ilinx, the feeling of vertigo or giddiness that accompanies, for example, riding a merry-go-round or sky-diving. More relevant to the kinds of language play we are considering here, Cook also refers to the feeling of “flow" theorized by Csikszentmihalyi, that comes from engaging well-honed talents and skills. This might account for the pleasure young children derive from reciting "tonguetwisters” and riddles, and adults get from “verbal dueling” and other exercises of verbal wit.

Of even greater interest for the present purpose are Cook’s (2000) observations about the subversion of the expected relationship between language and reality. Puns, rhyme, and rhythm require that words be chosen, not so much for their meaning as for their formal qualities, which are usually independent of meaning. Cook analyzes in some detail the nonsense rhyme, "The Owl and the Pussycat, in which the entire "story” is developed according to the requirement of the rhyme itself rather than of any objective sense. "The fiction thus created (to the extent that it is constructed on the basis of sound and abstract structure rather than probability or a previously constructed imagined world) thus seems to incorporate a wild and random element, to be controlled by language itself rather than by reality or the will of the writer” (2000, p. 49). Cook claims that this 
subversion of the normal relationship between word and meaning, and the randomness it introduces into speech and writing, have brought puns down from their earlier status as an element of high literary form (beloved by Shakespeare among others) to a present low status as groan-inducing verbal slapstick. More generally, by inducing a shift from a conventional and expected frame to an unexpected and often at least mildly counternormative frame, many genres of humor and word-play (especially irony) have a doubly subversive effect with respect to accepted social norms and expectations (Ritchie, 2005). On the one hand, these jokes and quips sometimes reveal a possible "truth" contrary to accepted and taken-for-granted ideals; on the other hand, they enlist the listeners in the implicit contradiction of the accepted social reality.

Adoption of a rhyme or alliteration scheme, a meter, or any other formal "rules" for composing a narrative or poem, making a quip or delivering the punch line of a joke inverts the usual relationship of language to reality and creates a new realm of possibilities and imagination. Cook suggests that, as language is more fully mastered, its possibilities become more constrained by meaning, and claims that this explains at least in part the sense of adulthood as a time when the magic of childhood is lost. Conversely, it would seem that the relaxation of meaning constraints and imposition of formal constraints in word play may well help adults to recapture this “lost innocence,” at least for a while. The most successful children's books and movies are often those in which the language play is sufficiently clever that adults can tolerate -even actively enjoy reading or viewing them with their children again and again. For several decades a large portion of the market in “children's literature” has consisted of picture books purchased by adults as gifts for other adults. 
Yet another source of pleasure in language play that has not been treated extensively in the play literature is pattern completion. The more complex the pattern, the greater the contextual effects (Sperber \& Wilson, 1986) and the greater the resultant feeling of satisfaction (Ritchie, 2005; 2006). The pleasure that comes from the unexpected burst of meaning when the punch-line of a joke, the solution to a riddle, or the final line of a haiku ties together several themes is very likely further enhanced by the pleasure of exercising one's own skill through participation in the pattern-completion.

\section{Idioms.}

The creative use of language - at any level from phonology to pragmatics - is a natural part of discourse. Speakers - some more than others - invent words and phrases to force us to pay attention, to amuse us, to astonish us, and to challenge us. And they create new ways to convey old meanings for the sheer joy of invention... Idioms are the poetry of daily discourse. (Johnson-Laird, 1993, p. ix.)

Idioms are more or less fixed expressions, often used, understood, and analyzed by linguists as units. Phrases considered to be idioms can be classified in terms of their compositionality, semantic transparency, and degree of metaphoricity (Cacciari, 1993; Glucksberg, 1993; 2001). Glucksberg (2001) gives as an example of a completely nondecomposable expression, "by and large," which must be treated as a single semantic unit, and does not map onto any readily-determined metaphor vehicle. "Kick the bucket" sounds metaphorical, but it is difficult to map onto a metaphor vehicle. However, "kick the bucket” does lend itself to some syntactic flexibility: It can be used in various tenses (“he is likely to kick the bucket any day now”) and even allows some semantic 
flexibility: (“John! Good to see you - I heard you'd kicked the bucket!” “Nope. Barely nudged it.”)

"Spill the beans" seems almost as semantically opaque, but subjects can decompose it into semantic units that can be mapped onto metaphor vehicles: "Spill” can be mapped onto "tell" (and is sometimes used independently, as in "Spill it!" or in other combinations such as "he spilled his guts") and "beans" can be analyzed in terms of secrets that are difficult to recall once they have been revealed (Glucksberg, 2001). Moreover, "spill the beans” allows a good deal of adaptation to the needs of actual discourse: “He didn’t spill a single bean” (Glucksberg, 2001); also, “No bean-spilling, now!" “Don’t worry, I don’t have any beans to spill.”

It appears that some idioms are "dead” metaphors, inasmuch as their vehicles have become lost; few people recall the basis for "block-buster," and idioms like "kick the bucket” or “the goose hangs high” (from Keysar and Bly, 1999; but see Gibbs, 1998) seem forever lost. Even "toe the line" is as often understood (and written) as "tow the line”: As discussed in the preceding, each version can be readily mapped onto a metaphor vehicle, but they map onto different vehicles, with slightly different entailments (Ritchie, 2006). On the other hand, Gibbs (1993; 2006) provides substantial evidence that the interpretation of many idioms involves activation of underlying conceptual metaphors, often at a subconscious level.

\section{Metaphor Play.}

An exchange heard on a street corner in a small southern Indiana town:

S: “Howdy John, how doin’?”

J: "Fine as frog's hair, Skeeter. You?" 


\section{S: "Fit as a fiddle!"}

At first glance, "fit as a fiddle” seems the less problematic of the two idioms; it is familiar in most parts of the United States, and can be traced back at least as far as $17^{\text {th }}$ century England. Even so, it is far from clear exactly what it means to be "fit as a fiddle!” Especially in contemporary U.S. society with our spas and fitness centers, “fit” is easy enough - or is it? Is Skeeter really claiming to be in top physical condition? Or is he claiming to be "fit for duty" (going back to an earlier sense of the term), or even, getting closer to the literal meaning of the term, "fitted" to his present task, whatever that is? Intuitively we suspect that he is claiming none of the above, but rather claiming a generally agreeable state of physical health and emotional mood. Here, perceptual simulators theory (Barsalou, 1999; Ritchie, 2006) may help. It would seem that "fit" activates a set of visceral, emotional, and even motor response simulators that, as a group, help to express what Skeeter is feeling at the moment.

But why fit as “a fiddle”? Most contemporary speakers would probably not even consider this question, but rather take the expression as an idiom (Glucksberg, 1993; 2001), a partially-lexicalized whole (Evans, 2006), and simply access the stored meanings of "general health and feeling of well-being." But it is likely that some readers and listeners process beyond that cursory level (Ritchie, 2006), in which case the best we can hope for is, again, the activation of secondary perceptual simulators associated with fiddles, which are likely to differ radically from person to person (Ritchie, 2006). These might include responses associated with the harmonics or tempo of fiddle (perhaps in contrast to violin) music, the feelings of gaiety and energy associated with listening to, dancing to, or playing fiddle music, or merely the generalized sense of tautness in a well- 
tuned fiddle. All of this is likely to be subtle and little of it is likely to become conscious to any listener other than a cognitive linguist.

"Fine as frog's hair" is more difficult. Like the "digging your own grave” example analyzed at length by Fauconnier and Turner (2002) or fixed idioms like "by and large” (Glucksberg, 2001), “fine as frog’s hair” seems at first glance to contain so many contradictions that a straightforward interpretation is impossible. “Digging your own grave,” as Ritchie (2006) shows, is actually much more straightforward than Fauconnier and Turner imply, and requires very little of the elaborate interpretive mechanism proposed by Fauconnier and Turner - once the connection is made to the many familiar metaphors based on digging in the earth for gold and other precious ores, digging tunnels, and other similar activities, and to the all-too-frequent risk of death from cave-ins, explosions, and other occupational hazards. "Fine as frog's hair," however, is not so easily untangled.

The problem begins with “frog's hair" - frogs are hairless amphibians. Since the comparison is to something that doesn't exist, frog's hair would be fine indeed! This gets us only slightly closer, since it would suggest that a person who is "fine as frog's hair" is so thin and wispy that he doesn’t exist - and that scarcely explains the sense of robust good health and agreeable mood conveyed by both expressions in this conversation. The gap can be only partially bridged by way of a pun on the word fine, which can mean both “very thin” and “very well.” These two senses are etymologically connected, since the positive aesthetic, moral, and emotional associations with fine themselves trace back to the higher valuation of fine thread over coarse thread, fine-milled flour over coursemilled flour, and “fine” facial features over "coarse” facial features. 
But why, of all things, “frog’s hair”? Why compare one’s physical, mental, and emotional state to the non-existent hair of a cold-blooded amphibian? Even after a fairly liberal merging of metaphorical extension and punning, the expression continues to defy interpretation: It is, in the ordinary sense of lexical meaning, as implied by the "conduit" metaphor for language (Reddy, 1993), “empty.” It has a clearly defined referent, and it activates a strong set of perceptual simulators (visual, tactile, emotional), but the referent is nonsensical and the simulators have no immediate relevance in the context.

What "fine as frog's hair" does offer the speaker is a pleasing alliteration and a musical rhythm - along with a subversive inversion of the customary relationship between form and meaning, like the Owl and the Pussycat, analyzed by Cook (2000), in the passage cited previously. Combining its alliteration, lilting rhythm, and amusing imagery with its nonsensical meaning, all of which activate strong emotional and introspective simulators, the expression takes on a playful, bantering quality that, in and of itself, conveys a joyous sense of well-being. "Fine as frog's hair," or at least fine enough to say "fine as frog's hair" instead of any of dozens of alternative responses, turns out to be very “fine” indeed. (See Figure 1.)

- Figure 1 about here -

We would suggest that this same sense of playfulness carries over into the remainder of the exchange. "How doin?" violates ordinary syntax in a way that is itself either a sign of unseemly haste (in too much of a hurry to speak the complete phrase, “how are you doing?”) or a sign of an upbeat, playful mood. (Other versions of the same question, also quite playful, are also heard throughout rural areas of the U.S., for example “how ya’ doin?” and the simple, declarative, "howdy,” sometimes embellished to 
"Howdy-Doody," calling to mind a children’s media figure from the 1950s). And the use of "fit as a fiddle," even if it seems more familiar to residents of other parts of the English-speaking world, is itself playful, and is very likely intended to be taken as a playful, bantering response. It may also be noted that, in a true spirit of playfulness, and contrary to the claims that adult play usually or always involves an agonistic (aggressively competitive) quality, Skeeter did not attempt to one-up John by responding with an even more outlandish or creative expression. Rather, by his up-take of the offered alliteration, Skeeter explicitly reinforces the bond of mutual affection. There is no aggression, competition for status, or other extrinsic quality to this exchange; it is pure, joyful, play. The absence of semantic meaning (task-oriented "content") permits attention to focus on the amusing and nonsensical simulators and on the pleasure of the exchange, thus greatly enhancing the mutual "grooming" function of the greeting ritual. Many expressions that appear to be "empty" can upon investigation, like "digging your own grave,” be unpacked and explained. “Happy as a clam” doesn’t make any sense at all (clams are not particularly noted for their positive emotional state) until one discovers that the original expression included a second phrase, "at high tide." Presumably, with several feet of water between them and hungry predators, and filled with tidbits of food, a clam is as happy as it is every likely to be. But this expression also illustrates the ambiguity of many idioms: A partially closed clam shell bears a slight physical resemblance to a person with a silly grin (or at least to cartoonists' renderings of such people). Alternatively, the fact that clams do not ordinarily move around very much might suggest a certain contentment with their location. Any and all of these subtle interpretations may play some role for some people in interpreting the expression - but 
for most people, the expression is probably enjoyed more for its playfulness, the amusingly absurd simulators it activates, than for any possible direct interpretation, and the mere fact that one uses this playful expression in lieu of some other, more lexically "meaningful” expression itself carries the primary meaning. Thus, for the purpose of a typical conversational exchange, "happy as a clam" is as "empty" of recoverable semantic meaning as "fine as frog's hair."

Many commonplace expressions have lost whatever metaphorical connections they may once have had and are repeated for the pure enjoyment of their nonsensical quality, and some may never have had a meaningful metaphorical basis: "Raining cats and dogs” comes to mind. It may have some historical mapping, but for most of us, it merely brings forth an amusingly silly image - and it sounds like the sort of thought one wishes to express during a summer thunder-shower. Like "raining buckets” and "a gullywasher,” this commonplace expression also plays upon the joy of overstatement, just as “it’s a bit damp out," spoken during the same kind of weather, plays upon the amusement of understatement. All of these, for a person reared in a speech community in which they are frequently encountered, also activate simulators associated with good humored sociability, and perhaps of “home.”

There is a fairly large class of figurative expressions that, like "fine as frog's hair," turn on absurd images. Some of these (“cute as a bug's ear” and “cute as a tick”) are, like “frog's hair” joyous, affectionate - and utterly absurd. Others ("in a gnat's eye”) are more apparently aggressive - but the apparent aggressiveness is moderated by the absurdity of the image. Often, playful mock-aggressiveness is made explicit as part 
of the fun, as in the tag line from a recent office Halloween party invitation: "We usually get about 30 children trick-or-treating, mostly small and quite tasty.”

\section{Implications for our understanding of figurative language.}

As we noted in the introductory section, traditional views of figurative language tended to regard metaphors as substitutable for or translatable into direct literal language, but more recent developments in cognitive linguistics have taken the approach that linguistic metaphors express underlying systems of conceptual metaphor. Recognizing the deliberately playful use of metaphors and other forms of figurative language leads us to suspect that a playfully creative approach to language is more widespread than has been previously recognized. Cook (2000) and Carter (2004) both point out that, as soon as children master an element of language, they immediately take delight in distorting it into absurdity. Carter (2004) calls attention to the widespread use of playful puns in commercial advertising and even shop names, giving examples such as A Cut Above for a hair stylist and an Irish petrol company called Emerald Oil. In the United States we have many taverns with names like "Dew Drop Inn” and “The Office” and singles' bars named “Meet Market.” Playful puns and metaphors are expected in sports journalism, often building on team names. Kovecses (2005, citing Aitchison, 1987) gives several examples, including “Air Force torpedoes Navy,” “Clemson cooks Rice,” “Cowboys corral Buffaloes,” and “Cougars drown Beavers.” Kovecses goes on to describe the amusingly creative metaphors and similes for which news anchor Dan Rather was famous: "hotter than a Laredo parking lot," "sweeping the South like a tornado through a trailer park," and "madder than a rained-on rooster," the latter a variant on the familiar idiom, “madder than a wet hen.” 
Norrick (1993) cites evidence from conversations among friends and family members in which puns and other forms of joking and language play are "chained," according to ad hoc rules in which one outrageous pun or quip follows another, just as, in the example analyzed in the foregoing section, Skeeter chained on John’s absurd but alliterative metaphor with a similar metaphor that built on the established alliterative pattern. A similar pattern of "chaining” is often observed when participants in a conversation play with what Lakoff and Johnson refer to as the "unused" parts of a metaphor: They give the following examples, based on THEORIES ARE BUILDINGS: "His theory has thousands of little rooms and long, winding corridors" and "complex theories usually have problems with the plumbing” (1980, p. 53). It is not clear from their discussion whether these examples were taken from actual discourse, but similar playful extensions of metaphors, as well as other linguistic patterns, are frequently encountered in everyday talk.

Glucksberg (2001) gives several examples of play with idioms, including "he didn’t spill a single bean,” previously discussed. More fun is his examples of newspaper headlines that distort common idioms to great rhetorical effect (p. 87), "Bulls Shove Chicken Little Aside” and “Main Street bulls take bears by the horns.” On p. 76, Glucksberg provides his own playful distortion of a commonplace idiom, in this case the title of a well-known Browning sonnet, converted in his sub-heading to "How are Idioms Understood? Let Me Count The Ways.”

Several examples of spontaneous play with idioms in actual conversations can be found in Gamson (1992). For example, at the end of a modified focus group conversation (in which the participants know each other prior to and outside of the 
research setting), the participants, a group of middle-aged firefighters, are reflecting on the focus group experience (p. 23):

Bill: I’ve been enlightened.

Paul: I enjoyed it.

Ken: I didn’t pull any punches anyways, so it's nice to be able to get other people

Joe: You didn’t throw any either.

\section{(laughter)}

Cameron (2007) has demonstrated the value of identifying patterns of metaphor use, re-use, and transformation for understanding the co-creation of social reality within a particular, culturally-situated conversation. The conversations analyzed by Norrick (1993) and Carter (2004) suggest that it will be equally valuable to identify and analyze patterns of playful transformations of both sense and nonsense as people, engaging in everyday conversations, invent, repeat, and transform playful and metaphorical expressions. In the example from Gamson, both Ken’s comment and Joe’s come-back are based on ARGUMENT IS COMBAT (Lakoff \& Johnson, 1980). Joe’s come-back reinforces the simulators associated with conventional COMBAT metaphors, and in other situations could be considered quite hostile, but here appears as a form of affectionate teasing that seems both to mitigate the somewhat serious, even gushy, tone of the preceding (“I’ve been enlightened”) while underscoring the group solidarity and reinforcing the group’s comfort with each other and with what has gone before. In another example from Gamson (1992, also p. 23), a group of women office workers are reflecting on the focus group experience: 
Ida: This was wonderful.

Nancy: Invite us back on different topics. This is really interesting because I tell you, I hate to go out and sit around and talk because most conversations with the people I chum with are totally boring.

Ida: Oh, poor baby.

The idiom, "poor baby" can be used either as a direct expression of sympathy or, as here, as an ironic comment on the previous speaker's complaint. Here, as with Joe's response to Ken in the preceding, it is clearly intended - and taken - not as hostile criticism but rather as a softening of Nancy's exaggerated characterization of her previous conversations, and as a moderation of the somewhat gushing tone of previous comments. As Norrick (1993) points out, this kind of apparently hostile teasing, when used within a circle of friends, can reinforce solidarity by demonstrating the underlying trust and confidence group members hold for one another. Incidentally, the conversation reported by Gamson continues with a partial repair and reinstatement by Nancy, supported by two other participants:

Nancy: It's usually gossip, and I hate gossip.

Arlene: That is boring.

Ruth: This was the most intelligent night for a long time.

It seems obvious that playful repetitions and transformations of figurative language will frequently be observed in non-serious discourse; they may also be observed in very serious discourse, in situations in which a brief bit of language play may serve to ease tension or generate social solidarity. Indeed, playful language is often heard at 
funerals - and the entire novel, Finnegan's wake (Joyce, 1999), is based on the use of playful, often bawdily playful, language at funerals and wakes in Irish culture.

Many expressions treated as conceptual metaphors, even if they have etymological roots in an observed correlation in experience, have become transformed into play, and are used, enjoyed, and repeated by contemporary speakers as much for their playful effects as for their possible conceptual mappings. These playfully distorted metaphors are often used in a way that at the very least seems "empty" of conceptual “content.” This may help explain some of the anomalous results of research in which subjects are asked to provide interpretations for metaphorical expressions. "Fine as frog's hair” means “fine as frog's hair.” What more is there to say? Insisting that an informant “explain” a playful (but semantically empty) metaphor of this sort is as likely to produce fanciful nonsense as anything like a linguist's coherent account.

Cook (2000) argues that the quasi-randomness permitted by the generally arbitrary relationship between word meanings and word forms is both subversive, in the sense that it undermines the customary and law-like relationship of form to meaning, and at the same time a potential source of cognitive flexibility and, by implication, creativity. According to Conceptual Metaphor Theory (Lakoff \& Johnson,1980), the conceptual metaphors that underlie all verbal metaphors are generated either by direct embodied correlations within experience or by way of combinations (“blends”) of such directly embodied conceptual metaphors. We would like to suggest that another source of linguistic metaphors may be the kind of language play that is rendered possible by the peculiar structure of human language, and by our heritage of intrinsically-motivated playfulness. It is also possible that some of these play-originated linguistic metaphors 
become, through extended cognitive processing, conceptual metaphors, thus reversing the causal and developmental direction suggested by Lakoff and Johnson. Just as a common form of object play consists of juxtaposing objects in unusual and apparently random combinations, so adults as well as children often juxtapose sounds, words, and phrases in unusual ways. Both adults and children transform familiar words, phrases, and even longer passages of language, as Dan Rather's transformation of "wet hen" into "rainedon rooster" illustrates. (Similarly, a transformed idiom recently spotted on a tee-shirt reads “Time flies when you're having rum.”) The results may be ludicrous, aesthetically pleasing, or occasionally comically insightful, as in the familiar quip, “dog, spelled backwards, is god."

Playful creation of metaphors in popular music. Literature and music are replete with playful, invented metaphors, like the string of satirical and bawdy love metaphors in Johnny Cash’s "Flushed from the bathroom of your heart" (written by Clement, 1968). Virtually all of these, beginning with the title metaphor, can be readily mapped onto implicit conceptual metaphors, which activate complex simulations (Gibbs, 2006) that make perfect sense to anyone who has ever been jilted (and who hasn’t?) Some of the phrases (for example, "In the theatre of your love I lost my part") map onto familiar and widely-used conceptual metaphors; others attach familiar idioms to novel metaphors ("Up the elevator of your future I've been shafted" and "At the table of your love I got the brush off.") Still others create new metaphorical juxtapositions - all with familiar domestic images ("From the back door of your life you swept me out”; "I've been washed down the sink of your conscience.”) These absurd - yet somehow strikingly apt - metaphors are not unusual; similarly inventive juxtapositions frequently 
occur in everyday conversation, and when they do they are often picked up, remembered, repeated, and refined.

Appearing on an album that includes more standard songs like "Long black veil” and "Give my love to Rose," both the lyrics and the melody of "Flushed” seem designed to activate the standard country-western "heartbreak" script, and all of the metaphors activates intense, unpleasant, and with a couple of exceptions decidedly un-romantic simulations (Gibbs, 2006; Ritchie, 2006); some of these are quite complex. On the album this script is reinforced, and the comic interpretation itself activated, by the immediately preceding song, “Dirty old egg-sucking dog” and Cash’s introduction of the pair as “a couple of love songs.” The metaphors are distorted and rendered ludicrous in a way that seems closer to the genre of scatalogical rhymes created - and repeated - on schoolyards everywhere (Cook, 2000), thus subversively undermining the conventional heartbreak script - along with the maudlin metaphors so frequently pressed into its service.

It is relatively easy to construct a "blending” model (Coulson, in press;

Fauconnier \& Turner, 2002) of any of the lyrics, as illustrated in Figure 2.

- Figure 2 about here -

Figure 2 is, of course, simplified, but it could be replicated for almost every line in the song, all of which activate disgusting and unromantic simulators, and each of which contributes to a characterization of the ex-lover to whom the song is directed (heart like a sewer, like a depression-era charity, etc.) and of the jilted singer (“treated like crap”).

Even more interesting for our purposes is to consider the blend that constitutes the satire itself, illustrated in Figure 3. In general we do not find the case for the "generic space” stipulated by Fauconnier and Turner (2002) convincing; in our view Coulson’s (in 
press, Figure 8) analysis of Bill Clinton cartoons, along with most of the other "blending” analyses in the literature, seems entirely plausible without it (for a detailed discussion see Ritchie, 2004; 2006). But if we think of a "generic space” as something like a schema for a generalized situation exemplified by both of the "inputs" to the "blend," it is useful for analyzing satire. In Figure 3, two schemas are shown, one for song-writing conventions typical of country-western love songs, and one for conventional ideas about love on which these are based. The "love song" schema is based on and informed by the "love" schema and in turn informs typical conventional love songs. The satirical lyrics of "bathroom of your heart” are derived through opposition to the conventional love song schema, leading to an implicit blend that in turn comments on and criticizes both the conventions of love song writing and the conventional ideas about love. The humorous effects are achieved in part by the opposition between the actual lyrics and the ideals of the convention and in part by the wry opposition within the song between the images of the lover and her treatment of the singer, and the conventional ideals of romantic love.

- Figure 3 about here -

The "love song” schema is pre-activated by Cash's introduction and reinforced immediately by the first line, "From the back door of your life you swept me out dear" (which probably could appear in a conventional, non-satirical country-western love song) and reinforced by the melancholy tune. The contrasts are accentuated by the repetition of themes within the song ("washed down the sink," "flushed from the bathroom"). They are also accentuated by the references to more culturally conventional metaphors ("theatre of your love”). A third site of contrast comes in the lines that combine a conventional metaphor with a ridiculous one, for example "On the river of your plans I'm 
up the creek.” Finally, we can expect that the simulators associated with an egg-sucking dog, as well as the "comic song” schema, remain activated from the preceding song.

In her analysis of cartoons about Bill Clinton’s Monica Lewinsky troubles, Coulson (in press) describes a similar kind of mapping in which Clinton is linked by a “generic space” to his long-ago predecessor, George Washington, and argues that the mapping humorously makes fun of Clinton by comparing him to the "ideal” to which he is linked. But in the case of "Flushed from the bathroom of your heart" the effect is just the opposite: The mapping makes fun of the "ideal," and by implication reflects back on the generic schema itself. Serious damage is, of course, not done to the generic schema, as demonstrated by the presence of three songs in the traditional mold on the same album: The satirical word play is, here, "all in fun."

Consistent with Vervaeke and Kennedy’s (1996) claim that metaphorical expressions are sometimes selected for rhetorical effect, we propose that metaphorical expressions are often created (as well as transformed and repeated) out of playful intent. The playful creation, transformation, and distortion of metaphors and idioms happens in satire, in teasing, and in everyday conversation. The play motive may often be as important to the creation, repetition, and use of metaphors as any motive to convey or express a particular meaning. When metaphors are created, transformed, or repeated in conversation, the purpose and effect may be related to content ("task-oriented”) or it may be primarily related to the "grooming” function of interaction (Dunbar, 1996), enhancing social bonds by generating shared pleasure (Norrick, 1993). In the latter case, the absence of interpretable “content” may often contribute to the pleasurable, playful effect.

\section{Conclusion.}


We have argued that apparently metaphorical expressions of a certain class can be considered "empty" in the sense that they are recognized as metaphorical and are metaphorical, by any reasonable definition of metaphor, but are used less for their possible interpretable meanings than for the social and cognitive effects generated by the mere fact of their use in a particular discourse context. Consistent with Cook’s (2000) analysis of language play as upending the customary relationship between language form and sense, these expressions are often used and enjoyed as much for the way they sound (and perhaps the way it feels to utter them and to hear them) as for any actual meaning they might have to the speaker or listener. They are thus similar to children's incantations (“One potato, two potato, three potato, four...”) and skip-rope rhymes, to skat-singing and nonsense verse ("As I was sitting by the curb/ as quiet as could be/ a great big ugly man came up/ and tied his horse to me!” (Tripp, 1973, p. 7)). Another class of figurative expressions may be interpretable, but may still be used and enjoyed as much or more for their playfulness as for any possible metaphorical entailments. "In $a$ gnat's eye” can be interpreted - a gnat is very small so its eye must be even smaller - but we suspect the phrase is used and enjoyed more for the playfulness of the image it generates, and of the sounds of the words themselves. We suggest that any analysis of figurative language in discourse needs to embrace the possibility that some of the language used is chosen for, and interpreted in terms of, its playful qualities as well as or even in lieu of any possible metaphorical mappings.

Without denying that apparently playful communicative behavior is sometimes used for extrinsic purposes such as assertion of interpersonal dominance or even outright aggression, we argue that playful communicative behavior is often intrinsically 
rewarding, if only as an incidental by-product of cognitive processes that originally evolved in response to survival pressures that may no longer be relevant. It is true that "for the fun of it" as a response to "why do people play" can become causally circular (Cook, 2000) - but if the "fun” of play can be explained, at least in principle, by other processes (such as the auto-release of endorphins), then it is not necessarily causally circular. We argue that acknowledging the fun that sometimes characterizes figurative communication may, at least in some circumstances, provide the most parsimonious explanation of the behavior and the most accurate understanding of the discourse.

Finally, we suggest that metaphors may originate not only in the experienced correlations within embodied experience and combinations of these primary metaphors, as stipulated by Lakoff and Johnson (1980; 1999) but also in the playful combination and distortion of words and phrases, on the basis of their sound, rhythm, and the images and perceptions they activate. This sort of language play may be artful and deliberate, as in the work of a poet, playwright, or journalist, but it may also be spontaneous and interactive, as in the casual conversations reported by Carter (2004), Norrick (1993), and others: In the final analysis, it is beside the point whether the results are actually semantically “empty,” as our title suggests. Either way, artful and deliberate or spontaneous and serendipitous, "empty” of content or with unattended or weakly attended content, if the effect is appealing and memorable, the result may enter the language and join the repertoire of expressive resources available to members of the language community, along with the pre-existing stock of idioms (some based on metonyms and some on embodied conceptual metaphors), and not easily distinguished from them. To ignore the play motive in metaphor creation and use is not only to "miss half the fun" of 
it - in many cases it may also be to miss a good part of what is going on cognitively and socially. 


\section{References.}

Aitchison, J. (1987). Words in the mind. Oxford: Blackwell.

Barsalou, L. (1999). Perceptual symbol systems. Behavioral and Brain Sciences, 22, 577-609.

Bateson, P. (2005). The role of play in the evolution of great apes and humans.

Pp. 13-26 in Pellegrini, A. D., and Smith, P. K., Eds. The nature of play: Great apes and humans. NYC, NY: The Guilford Press.

Cacciari, C. (1993). The place of idioms in a literal and metaphorical world. Pp. 27-56 in Cacciari, C., and Tabossi, P., ed., Idioms: Processing, structure, and interpretation. Hillsdale, NJ: Lawrence Erlbaum Associates.

Cameron, L. J. (2007). Patterns of metaphor use in reconciliation talk. Discourse and Society, 18, 197-222.

Carter, R. (2004). Language and creativity: The art of common talk. NYC, NY: Routledge.

Chiappe, D. L., and Kennedy, J. M. (2001). Literal bases for metaphor and simile. Metaphor and Symbol, 16, 249-276.

Clement, J. (1968). Flushed from the bathroom of your heart. From Johnny Cash at Folsom Prison. New York, NY: Sony Music Entertainment Inc.

Cook, G. (2000). Language play, language learning. Oxford, UK: Oxford University Press.

Coulson, S. (In Press). What's so funny: Conceptual Blending in Humorous Examples. In V. Herman, (Ed.) The Poetics of Cognition: Studies of Cognitive Linguistics and the Verbal Arts. Cambridge University Press. 
Dunbar, R. (1996). Grooming, gossip, and the evolution of language. Cambridge, MA: Harvard U. Press.

Evans, V. (2006). Lexical Concepts, Cognitive Models and MeaningConstruction. Cognitive Linguistics, 17, 491 - 534.

Fagen, R. (1995). Animal play, games of angels, biology, and Brian. Pp. 23-44 in Pellegrini, A. D., ed., The future of play theory: A multidisciplinary inquiry into the contributions of Brian Sutton-Smith. Albany : State University of New York Press.

Fauconnier, G., and Turner, M. (2002). The way we think: Conceptual blending and the mind's hidden complexities. New York, NY: Basic Books.

Gamson, W. A. (1992). Talking politics. Cambridge, UK: Cambridge University Press.

Gibbs, R. W. Jr. (2006). Metaphor interpretation as embodied simulation. Mind and Language, 21, 434-458.

Gibbs, R. W. Jr. (1998). The fight over metaphor in thought and language. Pp. 88-118 in Katz, A. N., Cacciari, C., Gibbs, R. W., and Turner, M., eds., Figurative Language and Thought (Counterpoints, Cognition, Memory and Language). Oxford, UK: Oxford University Press.

Gibbs, R. W. Jr. (1994). The poetics of mind: Figurative thought, language, and understanding. Cambridge, England: Cambridge University Press.

Gibbs, R. W. Jr. (1993). Why idioms are not dead metaphors. Pp. 57-78 in Cacciari, C., and Tabossi, P., ed., Idioms: Processing, structure, and interpretation. Hillsdale, NJ: Lawrence Erlbaum Associates. 
Glucksberg, S. (1993). Idiom meanings and allusional content. Pp. 3-26 in

Cacciari, C., and Tabossi, P., ed., Idioms: Processing, structure, and interpretation. Hillsdale, NJ: Lawrence Erlbaum Associates.

Glucksberg, S. (2001). Understanding figurative language. Oxford, UK:

Oxford.

Glucksberg, S., and Keysar, B. (1993). How metaphors work. In A. Ortony (Ed.), Metaphor and thought ( $2^{\text {nd }}$ ed, pp. 401-424). Cambridge, England: Cambridge University Press.

Huizinga, J. (1955). Homo Ludens; A Study Of The Play-Element In Culture. Boston, MA: Beacon Press.

Johnson-Laird, P. N. (1993). Forward. Pp. vii-x in Cacciari, C., and Tabossi, P., ed., Idioms: Processing, structure, and interpretation. Hillsdale, NJ: Lawrence Erlbaum Associates.

Joyce, J. (1999). Finnegan’s wake. New York NY: Penguin.

Keysar, B., and Bly, B. M. (1999). Swimming against the current: Do idioms reflect conceptual structure? Journal of Pragmatics, 31, 1559-1578.

Kohn, A. (1986). No Contest : The Case Against Competition. Boston : Houghton Mifflin.

Kovecses, Z. (2005). Metaphor in culture: Universality and variation. Cambridge, UK: Cambridge University Press.

Lakoff, G., and Johnson, M. (1980). Metaphors we live by. Chicago, IL: University of Chicago Press. 
Lakoff, G., and Johnson, M. (1999). Philosophy in the flesh: The embodied mind and its challenge to western thought. New York NY: Basic Books.

Lee, D. (1986). Language, children \& society: An introduction to linguistics \& language development. New York, NY: New York University Press.

Malaby, T. (2006). Parlaying value: Capital in and beyond virtual worlds. Games and culture, 1, 141-162.

Malaby, T. (2007). Beyond play: A new approach to games. Social Science Research Network, id922456.

Norrick, N. R. (1993). Conversational joking: Humor in everyday talk. Bloomington, IN: Indiana University Press.

Reddy, M. J. (1993). The conduit metaphor: A case of frame conflict in our language about language. In Ortony, A. (ed.), Metaphor and Thought, $2^{\text {nd }}$ Ed, pp. 164201. Cambridge, England: Cambridge University Press.

Ritchie, L. D. (2006). Context and Connection in Metaphor. Basingstoke, UK: Palgrave Macmillan Ltd.

Ritchie, D. (2005). Frame-shifting in humor, irony and metaphor. Portland, Oregon: Portland State University. Metaphor and Symbol, 20, 275-294.

Ritchie, L. D. (2004) Lost in "Conceptual Space”: Metaphors of Conceptual Integration. Metaphor and Symbol, 19, 31-50.

Ritchie, L. D. (2003a). Categories and Similarities: A Note on Circularity. Metaphor and Symbol, 18, 49-53. 
Ritchie, L. D. (2003b). “ARGUMENT IS WAR” - Or is it a game of chess?

Multiple meanings in the analysis of implicit metaphors. Metaphor and Symbol, 18, 125146.

Sharman, J. (1975). Rocky Horror Picture Show. Hollywood, CA: Twentieth Century Fox.

Sherzer, J. (2002). Speech play and verbal art. Austin, TX: University of Texas Press.

Sperber, D., and Wilson, D. (1986). Relevance: Communication and cognition. Cambridge, MA: Harvard University Press.

Sutton-Smith, B. (1995). Conclusion: The persuasive rhetorics of play. Pp. 275296 in Pellegrini, A. D., ed., The future of play theory: A multidisciplinary inquiry into the contributions of Brian Sutton-Smith. Albany : State University of New York Press.

Tripp, W., comp. (1973). A great big ugly man came up and tied his horse to me: A book of nonsense verse. Boston, MA: Little, Brown, and Co.

Vervaeke, J. and Kennedy, J. M. (1996). Metaphors in language and thought: Falsification and multiple meanings. Metaphor and Symbolic Activity, 11(4), 273-284. Wise, R. (1979). Star Trek: The Motion Picture. Hollywood, CA: Paramount Pictures.

Zillmann, D., and Cantor, J. R. (1976). A disposition theory of humor and mirth. Pp. 93-115 in Chapman, T., and Foot, H. (Eds.), humor and laughter: Theory, research, and applications. London, UK: Wiley. 
Figure 1 "Fine as frog's hair"

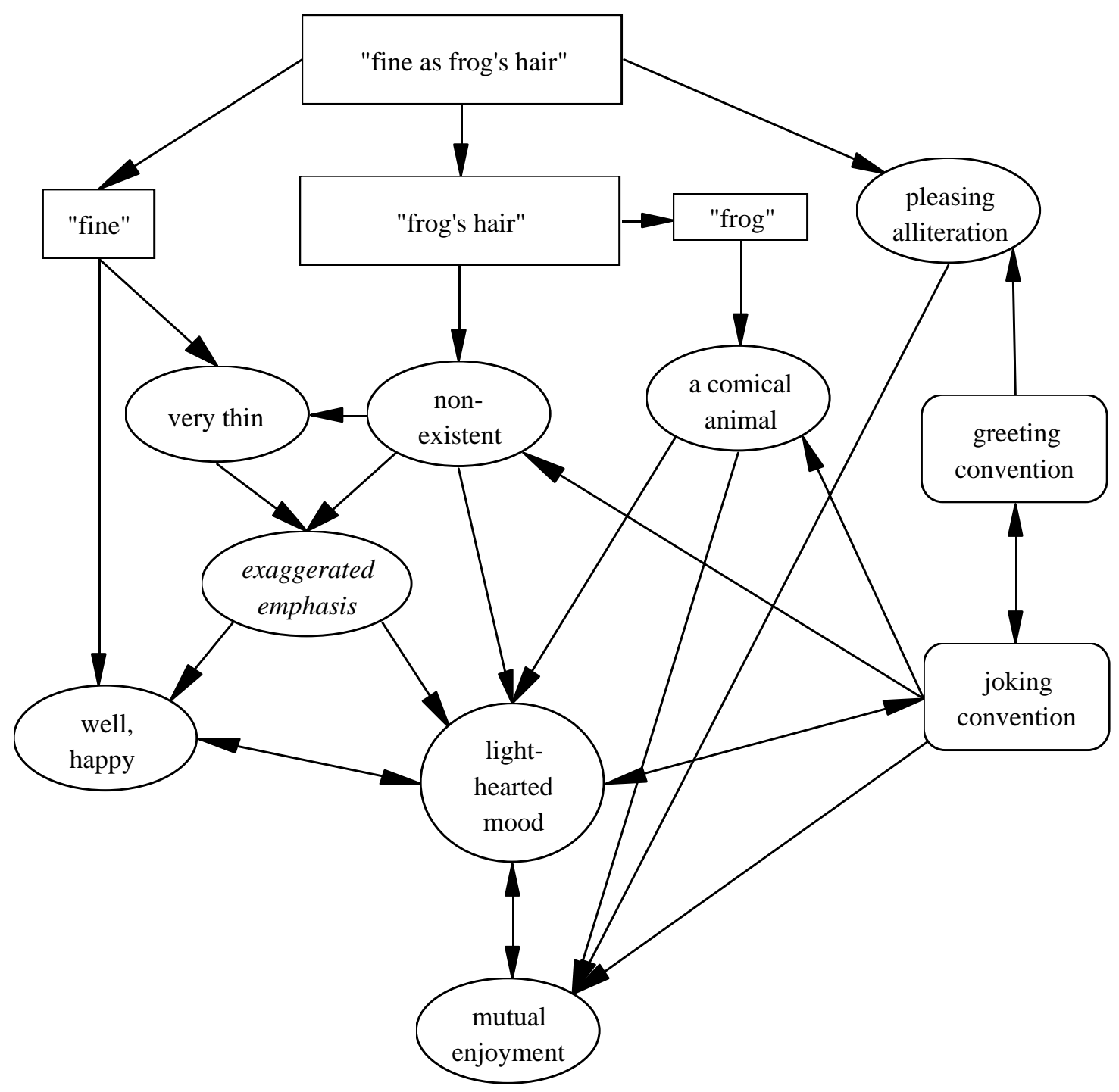




\section{Figure 2 Garbage disposal}

In the garbage disposal of your dreams I've been ground up dear

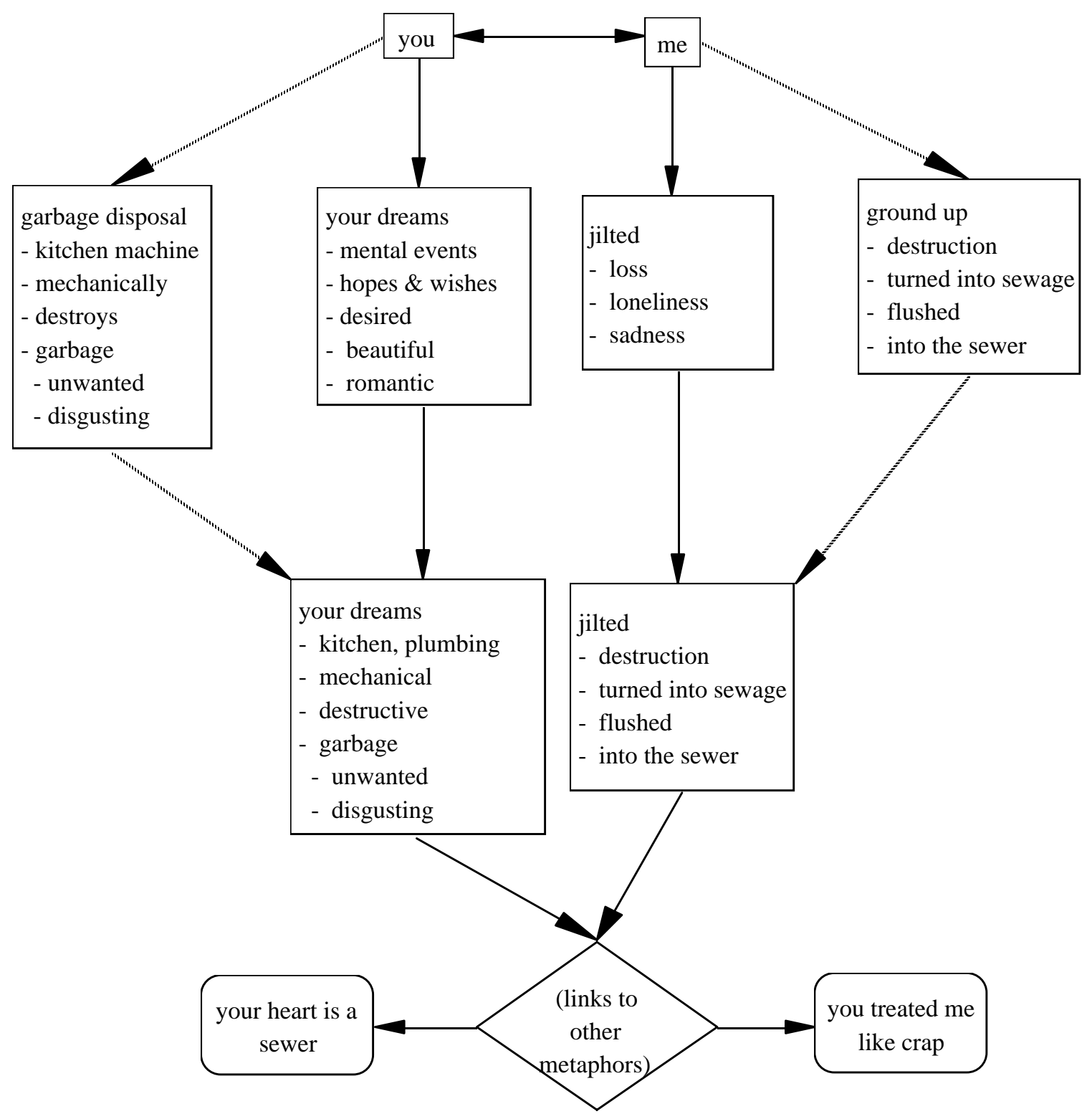


Figure 3 Satirical lyrics

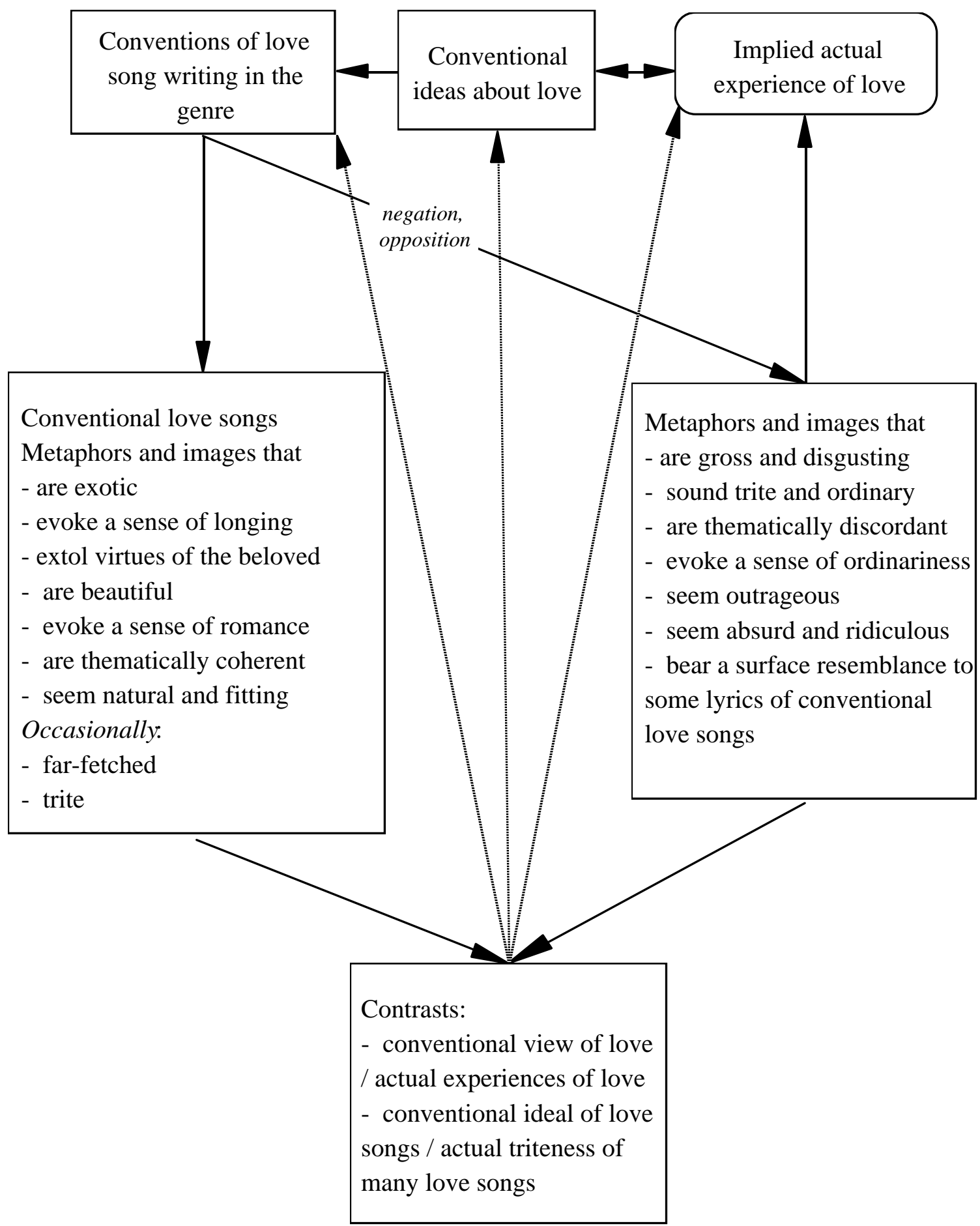

\footnotetext{
${ }^{1}$ Many theorists might resist including poetry or rhetoric within the definition of play, on the grounds that they are "serious," but it is difficult to come up with a justification for excluding them.
} 